\title{
Application of demand response to improve voltage regulation with high DG penetration
}

\author{
Chittesh Veni Chandran \\ Technological University Dublin, chitteshvc@gmail.com \\ Malabika Bassu \\ Technological University Dublin \\ Keith Sunderland \\ Technological University Dublin, keith.sunderland@tudublin.ie
}

See next page for additional authors

Follow this and additional works at: https://arrow.tudublin.ie/engscheleart2

Part of the Electrical and Electronics Commons, Power and Energy Commons, and the Systems and Communications Commons

\section{Recommended Citation}

Chittesh Veni Chandran, Malabika Basu, Keith Sunderland, Shivananda Pukhrem, João P.S. Catalão, Application of demand response to improve voltage regulation with high DG penetration, Electric Power Systems Research, Volume 189, 2020, 106722, ISSN 0378-7796, https://doi.org/10.1016/ j.epsr.2020.106722.

This Article is brought to you for free and open access by the School of Electrical and Electronic Engineering at ARROW@TU Dublin. It has been accepted for inclusion in Articles by an authorized administrator of ARROW@TU Dublin. For more information, please contact arrow.admin@tudublin.ie, aisling.coyne@tudublin.ie, gerard.connolly@tudublin.ie. Funder: FEDER (Portugal)

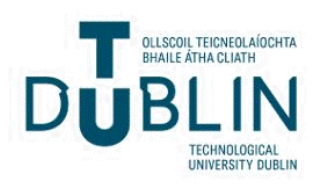




\section{Authors}

Chittesh Veni Chandran, Malabika Bassu, Keith Sunderland, Shivananda Pukhrem, and João Catalão 


\title{
Application of demand response to improve voltage regulation with high DG penetration
}

\author{
Chittesh Veni Chandran ${ }^{\mathrm{a}}$, Malabika Basu ${ }^{\mathrm{a}}$, Keith Sunderland ${ }^{\mathrm{a}}$, Shivananda Pukhrem ${ }^{\mathrm{a}}$, \\ João P.S. Catalão ${ }^{\mathrm{b}, *}$ \\ a TU Dublin, Dublin, Ireland \\ ${ }^{\mathrm{b}}$ Faculty of Engineering of the Universty of Porto and, INESC TEC, Porto, Portugal
}

\section{A R T I C L E I N F O}

\section{Keywords:}

Demand response

DG penetration

Mixed integer programming

Voltage stability

Voltage quality

\begin{abstract}
A B S T R A C T
The ability of a consumer friendly demand response based voltage control (DR-VC) program to improve the voltage regulation in a low voltage distribution network (LVDN) with high penetration of DG is investigated. The use of active and reactive power management to regulate the nodal voltage in a distribution network with simple incremental reduction algorithm, in conjunction with DR, is proposed as a solution for over voltage and undervoltage issues in the LVDN. The algorithm micromanages the load and generation in the network enabling the operator to utilize grid resources economically and efficiently while maintaining fairness between consumers with minimum inconvenience. The algorithm is tested on a representative.

74-load radial urban distribution network (Dublin, Ireland) using consumer load and DG generation profiles. The system is modelled and analysed using COM interface between OpenDSS and MATLAB. The DR is modelled through a mixed integer linear programming (MILP), implemented in CVX, such that consumer inconvenience is prioritized. The DR-VC algorithm is capable of regulating load and generation within normal operation limits during undervoltage and overvoltage scenarios.
\end{abstract}

\section{Introduction}

The amalgamation of distributed energy resources and smart loads into the distribution network has paved the way for new control strategies to address different network management issues at a granular level. An automatic and intelligent system, which monitors and controls the installed devices, could overcome the challenges faced by the low voltage distribution network (LVDN) under increased penetration of distributed generation (DG). The introduction of DG's and other active resources has made network voltage management a complicated task for the distribution system operator. In a radial distribution network, the lowest level of voltage occurs at the far end of the feeder and the highest level occurs at the transformer connection.

However, DG power injection implies that the lowest voltage can occur elsewhere and the highest voltage can occur at the point of DG connection [1,2]. Reverse power flow manifested by high DG penetration injecting currents results in voltage rise downstream [3,4]. The rise in voltage depends on the amount of current injection (which is a function of DG penetration) and the impedance of the circuit path where the reverse current flows. However, it can also be observed from
[4], that the change in voltage at a particular node can shift the overall voltage profile of all node's in the radial feeder network. This is further exasperated by other modern residential loads like electric vehicles (EV's) and smart loads.

\subsection{Voltage control methods}

The European standard EN 50160 requires that, the voltage magnitude variation in a LVDN should be less than $10 \%$ with a mean 10 minutes of root mean square (RMS) value and the rapid voltage changes should be less than 5\% [5]. Further, the supply voltage unbalance should be less than $2 \%$ for a mean of 10 minutes RMS. Maintaining these operation limits is the duty of a distribution system operator (DSO). Traditionally DSO maintains the voltage within the standard by regulating the operation of on load tap changer (OLTC) transformers, line voltage regulators, capacitor switch banks, line drop compensators etc. [3]. However, these are generally expensive resolutions.

Further, there are modern techniques proposed in literature, where active and reactive power control techniques of a grid tied inverter (GTI) connected DG are used to regulate the voltage in a LVDN. A local

\footnotetext{
* Corresponding author.

E-mail address: catalao@ubi.pt (J.P.S. Catalão).
} 
and centralised control scheme regulating the operation of PV - wind generator hybrid, EV and battery storage to maintain the voltage at point of common coupling (PCC) is proposed by [6]. The authors propose the regulation of the active and reactive power in the generators and battery storage to keep the voltage level within limits. A similar approach is also proposed by [7], where droop control is used to manage the active and reactive power of GTI to limit the voltage in an LVDN.

In [8], a positive, negative and zero sequence based current controller with reactive power compensation (filter capacitor) is proposed to maintain the voltage at the connection point. Techniques using the capabilities of a GTI are very cost effective, but increase the computational burden for the controller. Further, methods involving the droop characteristics of the GTI require manufacturers to assure a consistent operational characteristic. Reactive power control methods primarily depend on the (DG) GTI VAR rating and upstream transformer loading.

The active power curtailment method can be exploited at both generator (limited again by VA rating) and consumer load to manage the voltage violations. The German grid code as mentioned in [9], advocates for DG based GTI to manage LVDN voltage violations. Through single phase system reactive power control, unbalances are also created which could lead to neutral current at transformer neutral. Further, the operation of a GTI with active and reactive power control can create dynamic stability issues as discussed in $[10,11]$. However, this study does not consider the dynamic operation of the system nor any stability issues manifested.

The use of a communication network based infrastructure to regulate the output power could be simpler than many calculation based methods (e.g. droop control). These depend on the manufacturer descriptions of loads. Hence a DR based method utilizing communication based method can be an effective and economic solution for voltage control.

\subsection{Demand response}

Unlike the conventional structure where the consumers are always considered as passive, the modern distribution network operational architecture promotes consumer participation (and reward) for maintaining stable operation of the network. One such consumer participation to facilitate stable and economic operation of the network is called demand response (DR). Demand response, as one of the most promising (but underutilized) technology for network operation and management, alters the energy consumption pattern in response to price of electricity or peak load. Fundamentally, DR programs can be classified into two categories; incentive-based and time based programs.

The majority of techniques proposed are incentive based direct load control (DLC). Here, consumer loads are controlled remotely to achieve a certain objective while consumer receive incentive for the inconvenience caused.

The DR technology utilizes the consumer resources to achieve a variety of objectives. These range from peak load management, to solving reliability issues and many more [12-14].

Further, numerous techniques are also applied to achieve DR in literature. These include model predictive control [15], heuristic optimization based [16], agent based modelling [17], mixed integer programming [18] and machine learning based demand response [19] etc. However, the methodology applied to achieve the demand response is usually dependent on the objective/application and is generally chosen by the programmer (DSO/Aggregator). Moreover, selection is often based on knowledge and intuition.

Here, a mixed integer linear programming (MILP) is implemented using MOSEK solver in CVX toolbox in MATLAB environment. However, even with numerous proven technologies in literature, large scale implementation of a DR program is seldom observed. One major reason for this is considered to be consumer reluctance to such kind of load management plans due to the inconvenience caused.

\subsection{Consumers in $D R$}

The study performed by the authors in [20] shows that the participation of a consumer in DR will result in inconvenience, which in turn affects their engagement. Further, the authors in [21] indicate the importance of consumer awareness on the success of a DR program and propose an engagement plan based on thermostatic. The consumer behaviour based model presented in [22] again identifies the importance of consumer satisfaction on the success of a DR program. The paper also points out that the incentive based DR program has a relatively higher influence on achieving better consumer engagement. Indeed, "the industry is only at the beginning of learning to understand their customers and figuring out what people want to do" [23]. The requirements of people are so diverse and depend on social and demographic parameters leading to extreme difficulties in generalising an engagement plan/DR program. The European Commission [24], points out that, consumers should be given the right incentives to encourage more active engagement and contribution to system performance and stability. For instance, a survey conducted by Opower [25], shows the consumers feel it is important for suppliers to inform them about the critical periods and the associated tariff.

\subsection{Contribution}

This study utilizes an incremental reduction/increase based method in conjunction with DR to regulate the voltage profile in a radial LVDN feeder. Subsequently, the proposed method is tested on an urban distribution network.

The contribution of this study can be summarized as:

- The regulation of maximum and minimum voltage levels in the LVDN with an incremental reduction/increase of active power by curtailment/DR algorithm which simultaneously manage the load and generation

- Minimisation of Consumer inconvenience by a distinct DR application, that also takes care of grid stability and economic operation

The remainder of the paper is sectionalized to realise the above mentioned objectives. The next section details the modelling of the voltage quality constraints and the consumer friendly DR followed by results and discussion.

\section{Demand response - voltage control (DR-VC)}

The main objective of this paper is to indicate the applicability of a DR program to achieve necessary voltage regulation in a LVDN. There are many examples where the active power curtailment (load shedding) method has been employed to control the voltage in the LVDN [26]. The similar methodology is applied in a structured manner using the DR program. As well as, the voltage regulation can also be achieved by reactive power control. This section presents the theoretical background for voltage regulation with active and reactive power control. Thereafter, the paper will describe a modelling approach for DR-VC algorithm utilizing the active and reactive power management in a DG integrated LVDN.

A complete flow chart of the presented approach is given in Fig. 1.

\subsection{Voltage vs active and reactive power}

A two bus distribution system with embedded DG is given in Fig. 2. Under normal condition the power flow from bus 1 with voltage $V_{1}$ to bus 2 with voltage $V_{2}$ though the connected transmission line with ' $R$ ' and ' $\mathrm{X}$ ' as resistance and reactance respectively to feed the load connected at bus 2 .

Initially when DG is not injecting any power, active and reactive power flowing through the line connecting the bus 1 and 2 is given by 


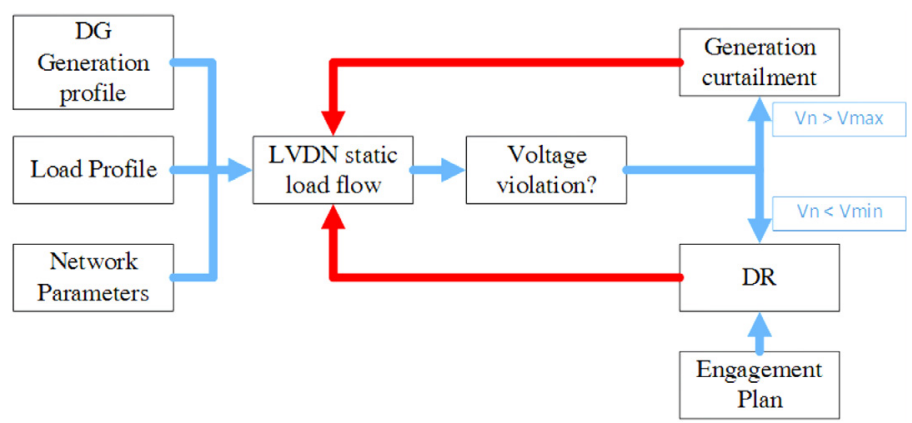

Fig. 1. Flow chart

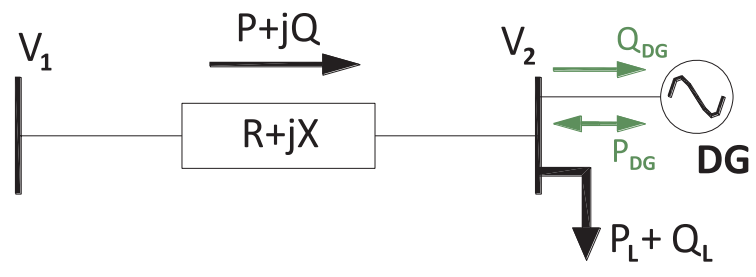

Fig. 2. Two bus power system with integrated DG

$P+j Q$, which is the same as the active and reactive power demanded by the load $P_{L}+j Q_{L}$ (ignoring transmission loss). The voltage drop at bus 2 is given by [26],

$\mathrm{V}_{1}-\mathrm{V}_{2}=\Delta \mathrm{V}=\frac{\mathrm{PR}+\mathrm{QX}}{V_{2}^{*}}$

Where, differentiating the above equation with respect to $\mathrm{P}$ and $\mathrm{Q}$ respectively gives,

$\frac{d \Delta V}{d P}=\frac{R}{V_{2}^{*}}, \frac{d \Delta V}{d Q}=\frac{X}{V_{2}^{*}}, \frac{\mathrm{d} \Delta \mathrm{V}}{\mathrm{dQ}}=\frac{\mathrm{X}}{\mathrm{V}_{2}}$

It can be observed that, the change in the voltage with respect to change in active power is proportional to the line resistance and reactive power is proportional to the line reactance. The dependency found between the reactive power and voltage in a transmission and sub transmission level [27] system is not found in the distribution system as LVDNs are generally of very short distance with a highly resistant component relative to the associated reactance when compared to transmission systems. In addition, the maximum loading capacity of the LVDN system is not bound by the voltage drop as the low $\mathrm{X} / \mathrm{R}$ values result in violations of thermal limits much sooner than voltage violations as load increases.

With the DG connected and injecting power, the Eq. (1) can be written as,

$$
\begin{aligned}
V_{1}-V_{2} & =\Delta V=\frac{\left(P_{L}-P_{D G}\right) R+\left(Q_{L}-Q_{D G}\right) X}{V_{2}^{*}} \mathrm{~V}_{1}-\mathrm{V}_{2}=\Delta \mathrm{V} \\
& =\frac{\left(\mathrm{P}_{\mathrm{L}}-\mathrm{P}_{\mathrm{DG}}\right) \mathrm{R}+\left(\mathrm{Q}_{\mathrm{L}}-\mathrm{Q}_{\mathrm{DG}}\right) \mathrm{R}}{\mathrm{V}_{2}}
\end{aligned}
$$

As mentioned before, the low value of ' $\mathrm{X} / \mathrm{R}$ ' makes the variation of active power a dominant factor in calculating the voltage drop. Now, when $P_{D G}$ is sufficiently large (reverse power flow), the right side of the equation becomes negative (assuming load is at unity power factor) showing that $V_{2}$ is larger than $V_{1}$. Thus, the high penetration of DG injecting high amount of active power would cause voltage at the end of feeder to rise. From Eq. (3), when $Q_{D G}$ and $Q_{L}$ are kept constant, voltage at node 2 can be regulated by varying either $P_{L}$ (demand response) or $P_{D G}$ (active power curtailment). Even though small, the reactive power variation in Eq. (3) also has a correlation with the voltage variation at node 2 . Hence, controlling the reactive power at the node and in the network can be utilized to regulate voltage up to a certain level (depending on the economics involved). The reactive power based voltage control is a very limited resource and is usually restricted to grid tied inverted based DG's GTI capability. This study assumes that the maximum available reactive power is up to $10 \%$ of the maximum rating of the plant in kVA.

The exact amount of active/reactive power change required to regulate the voltage at a certain node can be calculated from Eq. (3). Also, the literature [28] utilizes the computation of a voltage sensitivity matrix to calculate the active/reactive power required for necessary voltage regulation. However, unlike many transmission and sub transmission systems, the unbalanced nature of distribution networks may pose difficulties in expressing and solving system equations to compute a sensitivity matrix. Another well explored method available in literature is utilizing droop control which can provide the value of active/ reactive power required based on the droop characteristics of GTI of DG [7]. This method even, if simple to utilize, depends on accurate representation of droop characteristics of GTI manufactured by different manufacturers. Further, it has to assume that the droop characteristics do not change during the operation life time of GTI. The presented study utilizes an incremental reduction method to curtail the power injected by DG surrounding the overvoltage node without heavily penalizing the nearest DG.

\subsection{DR-VC algorithm}

In order to create a consumer-friendly DR program, a consumer engagement plan is set up for the consumer to choose the level of engagement/participation in the load management program. The engagement plan utilized in this study is created with consumer inconvenience as the contributing factor. The engagement plan can also be utilized for devising the incentive scheme which is not considered in this study. From socio economic studies, a persistent motivation for DR engagement occurs when there is a correlation between benefit and non-tangible gains for consumers, like environment benefits. Keeping this in mind, four engagement plans are considered for the presented study. The consumer participation is represented by tolerance $(\alpha)$ and is used by the DR program to obtain the desired load management, which in effect would help to maintain voltage within limits.

1 Super Green Savvy (SGS) ( $\alpha \in[0.2-0.5)$ ): consumers motivated by the social and environmental benefits of DR and are willing to tolerate high load reduction.

2 Green Savvy (GV) ( $\alpha \in[0.5-0.7))$ : consumers aware of DR benefits but not willing to tolerate SGS level.

3 Green Aware (GA) ( $\alpha \in$ [0.7-1)): consumers willing to test and participate but are skeptical concerning sacrificing their comfort.

4 Reluctant (R) ( $\alpha=1)$ : consumers not willing to participate in the DR program. They are not penalised but also, they do not benefit.

Assume a feeder feeding ' $n$ ' number of consumers in a LVDN network at any given time ' $t$ '. The total load on the network can be given 
by

$P_{\text {Total }}(t)=\sum_{j=1}^{n} P_{j}(t)$

where, $P_{j}$ is the power consumed by the $j^{\text {th }}$ consumer. Since this analysis is carried out at a steady state, time dependency is not a concern. The analysis concerns a LVDN prioritizing domestic households; the total load being a contribution of their ' $m$ ' number of devices per house. Moreover, the domestic loads are also categorised as controllable (C) and non- controllable (NC), where the former participates in the DR. Now the total load is given by,

$P_{\text {Total }}=\sum_{j=1}^{n}\left(\sum_{i=1}^{m} A_{i j}\left(P_{i j}^{N C}+P_{i j}^{C}\right)\right), \quad A \in(0,1) \mathrm{A} \in(0,1)$

The demand status vector $\left(A_{i j} \mathrm{~A}_{\mathrm{ij}}\right)$ is a time dependent demand status of $i^{\text {th }}$ device of $j^{\text {th }}$ consumer. The presented study assumes that ' $A$ ' is available ahead of time which is also a critical component for the success of any DR program. For GTI based DGs, such as solar photovoltaic, the total demand of the network can be described by

$P_{\text {Total }}=\sum_{j=1}^{n}\left(\left(\sum_{i=1}^{m} A_{i j}\left(P_{i j}^{N C}+P_{i j}^{C}\right)\right)-P_{j}^{D G}\right), \quad A \in(0,1)$

where, $P_{j}^{D G} \mathrm{P}_{\mathrm{j}}^{\mathrm{DG}}$ the active power injected by the DG. Currently we are not interested in the load reactive power demand as it is not considered as the controllable parameter (in this study). However, the reactive power $\left.\left(Q_{j}^{D G}\right) Q_{j}^{D G}\right)$ injected/absorbed by the GTI based DG can be regulated as per [29,9]. This study considers the power factor lower limit to 0.9 (leading/lagging), which means, the maximum amount of reactive power absorbed/injected is given by,

$Q_{\max }=-P^{D G} \sqrt{\frac{1}{\left(\cos ^{2} \theta\right)}-1}$, where $\cos \theta_{\min }=0.9$

\subsection{Undervoltage}

When an undervoltage is observed at any node, the primary assumption is that the network is heavily loaded and highly inductive. The initial response to bring the voltage back to the nominal lower limit without reducing active power is by changing the reactive power $\left(Q_{\max }\right)$ injection. If the under-voltage is not cleared by this adjustment, the DR is initiated, and load curtailment scheduled. The required amount of load reduction is set to $5 \%$ of total load and individual load reduction for each consumer based on their engagement plan is generated by using mixed integer linear programming (MILP). The MILP is implemented using CVX toolbox with Gurobi Solver in the MATLAB environment. The objective function for the DR is given by,

$\operatorname{minimize}\left(\sum_{j=1}^{n}\left(\alpha_{j} \Delta P_{j}\right)\right)$

The objective function minimization ensures that the total inconvenience caused to the consumers will be minimal and the load reduction is distributed according to the engagement plan. This objective is constrained by,

$\Delta P \leq 0.5 P_{\text {Total }}$

$0 \leq \alpha_{j} \leq 1$

$\Delta P \leq \sum_{j=1}^{n} \Delta P_{j}$

Maximum reduction of a single consumer is also restricted to $50 \%$ which ensures that the consumer with very low inconvenience would not have to suffer total blackout of non-critical load. Also, a fairness component is added to the algorithm which increment/decrement the tolerance value of a consumer for next interval based on the amount load reduction contributed and the amount of time it was reduced for.

$\alpha_{j}^{\text {new }}=\alpha_{j}^{\text {old }} \pm G_{1} \Delta P_{j} \pm G_{2} \Delta T_{j}$ where, $\quad 0 \leq \alpha_{j} \leq 1$

$G_{1}$ and $G_{2}$ can be tuned based on the system and the required flexibility in the system. Individual consumer reduction requests are sent to the consumer local controller to operate the device(s) necessary for the requested reduction.

\subsection{Overvoltage}

Overvoltage is generally associated with higher DG power injection at light load conditions, which cause a reverse power flow. With the reverse power flow, from [7] it can be observed that the voltage rise is highest at the end of the feeder. Now as an initial measure the operation of DG can be set at 0.9 leading power factor and absorb the reactive power (Eq. (7)).

If the voltage rise persists, the active power curtailment method is applied, where active power injections of DG connected to the overvoltage nodes are reduced to reduce the voltage. However, this introduces a dilemma as the overvoltage at the end of the feeder has contributions from all the consumers connected to the feeder. The presented study proposes an incremental curtailment technique to curtail the active power generation by DG's connected to the feeder. The proposed methodology introduces a relative fairness to the DG curtailment compared to many active power curtailment regulations. A flow chart of the proposed methodology is presented in the Fig. 1. The iterative loop successively reduces the DG output by $5 \%$ and checks the over voltage (as given in Eqs. 13 and 14). If overvoltage persists, each iteration increases the DG curtailment by $5 \%$. This incrementally reduces the active power injection until the voltage reaches the regulated limit.

$\Delta P_{i}^{D G}=0.05 P_{i}^{D G} \times C_{2} \quad \forall i \in\{0,1,2, \ldots, p\}$

$P_{i}^{D G}=P_{i}^{D G}-\Delta P_{i}^{D G}$

where $P_{i}^{D G}$ is the power injected by the DG connected at $\mathrm{i}^{\text {th }}$ node and ' $\mathrm{p}$ ' is the total number of PVDG in the feeder. The incremental reduction of DG active power to decrease voltage violation ensures a minimum amount of reduction would be imposed every time. Incremental reduction is achieved by iterating the value of $\mathrm{C}_{2}$ which takes integer values. As Eq. (3) suggests, voltage on node 2 decreases as generation at node 2 decreases. The algorithm (DR-VC) allows the operator to manage the voltage violation issue in the LVDN.

\section{Results and discussion}

The analysis was performed on a residential distribution network (shown in Fig. 3) with 9 (three-phase) pillars supplying 74 single-phase domestic customers through a $20 \mathrm{kV} / 400 \mathrm{~V}$ supply. A detailed description on modelling of the presented distribution network is given in [30]. The model, a radial feeder supplying 74 domestic customers, was implemented in OpenDSS simulation platform [31]. A randomly distributed set of single phase PVDG's are considered in the network connected to different consumers. The number of PVDG's installed has been varied to vary the penetration level in the network.

The level of voltage profile has been dependent on the amount of PVDG penetration, and hence, the presented study has adopted limits of hosting capacity suggested by the authors in [7]. For simplicity the stochasticity associated with consumers load consumption pattern is ignored, and all consumers are modelled to have the same generalised daily load curve. The maximum loading of the LVDN is restricted by the thermal limit or the current carrying capacity. This network has the maximum current carrying capacity limited by the first section (line $\mathrm{AB})$ and is $478 \mathrm{~A}\left(185 \mathrm{~mm}^{2} \mathrm{XLPE}\right)$. This in turn limits the operating limit of the transformer to $210 \mathrm{kVA}$ even though it is actually rated at $500 \mathrm{kVA}$ 


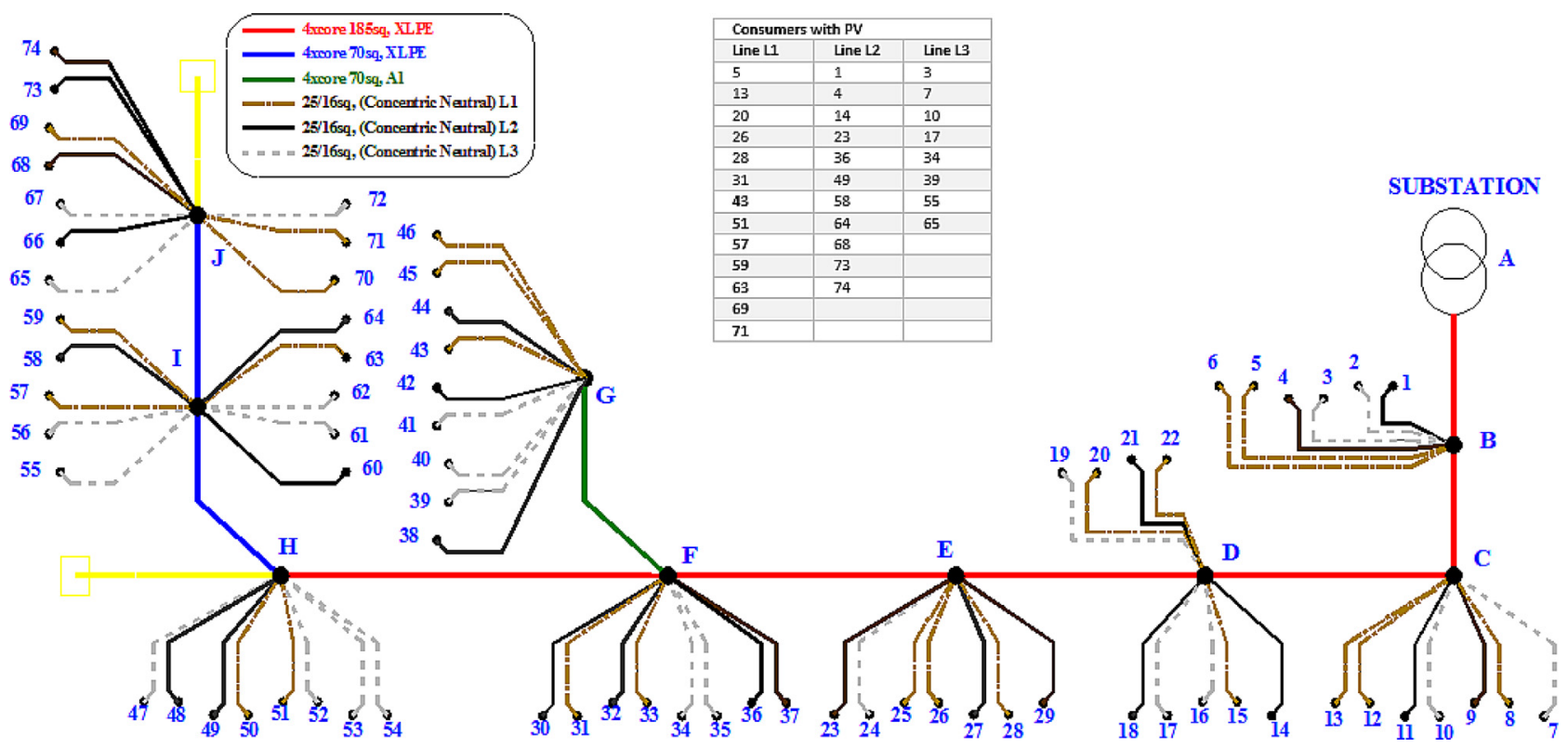

Fig. 3. Urban distribution network model incorporating the domestic load/PV profiles [7]

( 3 winding, 20kV/440V) capacity, but for certain cases the system has been loaded to $60 \%$ of the rating of transformer to observe the possible worst voltage violations.

The power output profile is also kept the same for all connected PVDG's with maximum allowed individual peak power rating of 5.75 $\mathrm{kVA}$. The generalized consumer load consumption curve and PV power output curve are shown in Fig. 4.

The generalized load curve was generated using an average model utilizing load consumption of 300 consumers recorded during a survey. The PV profile (scaled) was obtained from a measured data for a day in August 2010 for a $1.7 \mathrm{~kW}$ Saynno PV panel setup.

The simulation is performed for every 10 minute period, or. 144 simulation intervals per day. A DR program requires a predicted consumer demand, and hence, this study assumes that the consumer demand and the PVDG generation profiles are available ahead of time. This further enhances the application of the proposed DR-VC algorithm as the future condition of LVDN voltage profile is available to the operator to readjust anything if required. The distribution transformer (DT) is considered without on-load tap changer (OLTC) and is assumed to be operating at fixed voltage setting of 1.0 per unit (p.u). Generally, the regulation suggests a tolerance of $\pm 10 \%$ for LVDN voltage level, and hence, the upper limit is 1.1 p.u and lower limit is set to 0.9 p.u (light bounding). A scenario was also analysed to regulate the voltage profile between $1.05-0.95$ p.u as well to ascertain the capability of the algorithm to operate in tightly bounded conditions. Also, the $100 \%$ loading from hereon is just more than $60 \%$ of rating of DT.

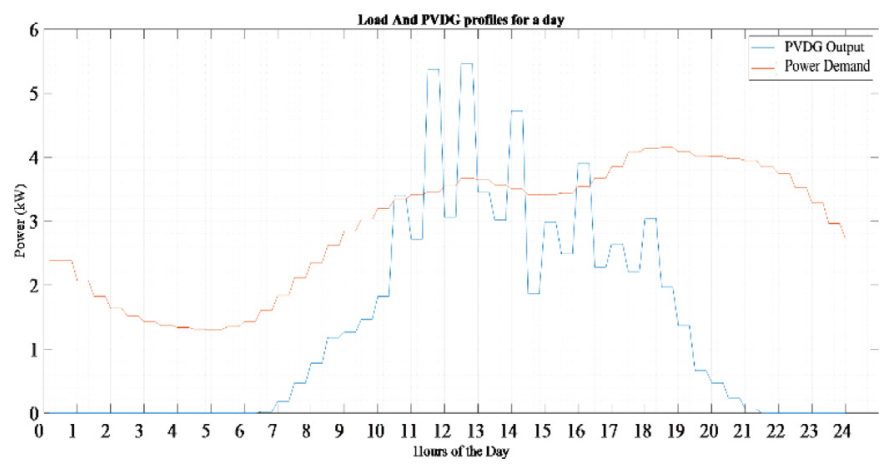

Fig. 4. Load and PVDG profile of a day
As suggested in [7], this study use 32 PVDG's randomly distributed throughout the LVDN with maximum rating of 5.75kVA each and constituting a maximum generation of 184KVA in total. Different scenarios were simulated with a range of loading and generation levels as presented in Table 1. The LVDN is subjected to different levels of loading and DG penetration and the voltage of each phase at pillars 1 and 9 are noted. Pillar 1 being closest to the DT has minimum voltage drop/rise whereas pillar 9 has the highest variation in voltage magnitude. It can be noted that, with increase in loading, the voltage drops progressively increases/decreases with a constant trend. With PVDG generation operating at different levels, the voltage magnitude at pillar 9 varies cognizant of the amount of generation capacity (Table 1). An interesting observation from Table 1 is that, higher penetration of PVDG at high loading can compensate for the voltage drop at the pillar 9. Correlating with Eq. (3), the reduction of the active power component has a higher impact on voltage regulation. However, with light load, the voltage rise at the lower end of LVDN can increase and violate the upper voltage boundary.

Hence, managing the penetration level of DG's in the LVDN allows the operator to manage the loading of the system directly. If in complement with DR, the program can induce significantly less inconvenience for the network consumers.

Looking at the PVDG active power curtailment, with a 100\% PVDG and $0 \%$ loading scenario (Table 1), the active power injection of PVDG can be decreased (incrementally) to meet the upper boundary of voltage levels. As shown in Fig. 5, the DG output power in the network is curtailed to maintain the voltage within limits. The consumer DGs are still able to generate at least at $50 \%$ capacity to maintain the voltage at consumer nodes. The amount of active power curtailed is also significantly less. For tight bounding $\left(0.95<\mathrm{V}_{\mathrm{i}}<1.05\right)$, the amount of curtailed generation increases, and generation is significantly restricted. Fig. 6 and Fig. 7 illustrate the voltage profile at pillar 9 for phase A and C across a single day for a range of scenarios. Phase B is not shown here as it is similar to phase $C$. The voltage regulation achieved during high DG penetration and high loading is also represented while utilizing the proposed algorithm.

Table 1 illustrates DG curtailment initiation on the 100\% DG penetration scenario. Demand response is applied at low DG penetration levels as the lower boundary voltage violation occurs at high load and low DG levels.

The MILP-DR applied to reduce the load during under voltage 


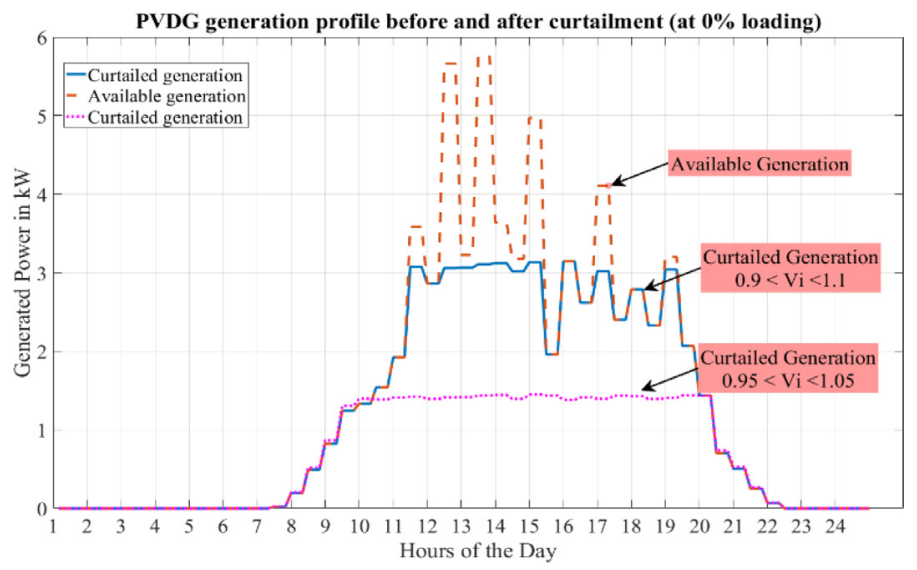

Fig. 5. PVDG generation and curtailment with light and tight bounding for consumers at pillar 9

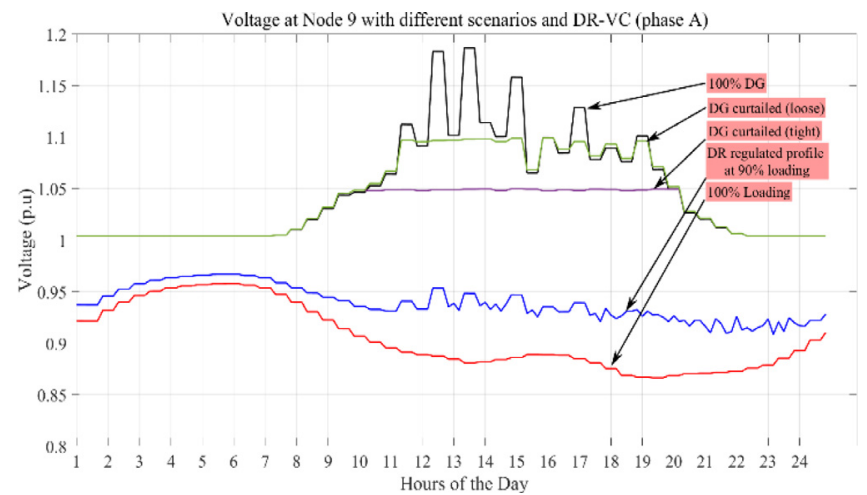

Fig. 6. Voltage at node 9 (Phase A) under different scenarios

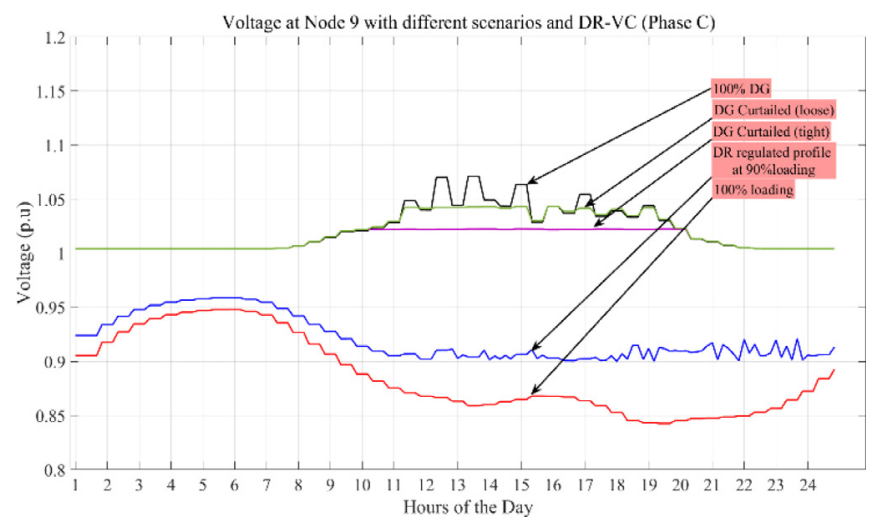

Fig. 7. Voltage at node 9 (Phase C) under different scenarios

scenario utilizes the consumer engagement plans to decide the amount of consumer participation and engagement. The fairness algorithm, by increasing/decreasing the tolerance value, ensures the avoidance of consumer overburdening. The DR essentially drives an active power curtailment method in the LVDN to minimize the overall load on the network.

The use of an engagement plan based DR enhances the consumer acceptance of the DR program. There are four different engagement plans assigned arbitrarily across the 74 consumers.

Fig. 8 shows load reduction and the associated tolerance value change for a consumer engaged in the super green savvy engagement plan. It exemplifies the capability of the proposed algorithm to regulate the participation of consumers. The corresponding voltage profiles of each phase at pillar 9 is given in Fig. 6 to Fig. 7 for 100\% loading and $20 \%$ DG.

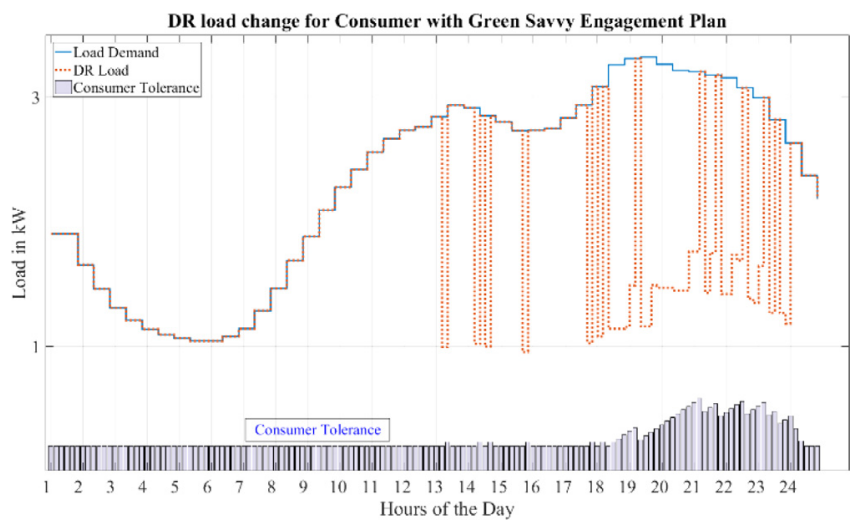

Fig. 8. Demand and DR allowed load for consumer with super green savvy engagement plan and their corresponding tolerance change

\section{Conclusion}

In this paper a coordinated DR based incremental curtailment method is applied to regulate the voltage profile in LVDN. The voltage profile of LVDN is analysed at different levels of loading and PVDG penetration on a 74 house radial urban distribution network. With increased loading, the network voltage levels are lowered with distance from the DT, but with DG active power injection the voltage profile is regulated much better. Yet again, with low loading the high active power injection of DG causes the voltage profile to breach the upper boundary tolerance. The proposed algorithm is tested with different scenarios of voltage violation and has showcased its capability to manage the voltage levels through active power management. With overvoltage, DG incremental active power curtailment method ensures that the burden of reducing the nodal voltage is not left solely to the DG/consumer connected to the node experiencing overvoltage. When under voltage is prevalent, a MILP DR is employed, which reduces the consumer load based on the engagement plan chosen by the consumer. The engagement plan uses a tolerance value to represent the level of inconvenience a consumer has to tolerate, while participating in a DR program. In short, if implemented in a complementary way, the consumer friendly DR-VC algorithm can regulate the LVDN operating voltage levels by micromanaging the consumer resources (Load and generation). The approach opens up economies to both consumers and DSO.

Table 1.

\section{Declaration of Competing Interest}

The authors declare that they have no known competing financial 
Table 1.

Voltages at 1st and last pillar at different loading levels

\begin{tabular}{|c|c|c|c|c|c|c|c|}
\hline \multirow[t]{2}{*}{$\%$ PVDGOutput } & \multirow[t]{2}{*}{ Loading \% } & \multicolumn{3}{|c|}{$\begin{array}{l}\text { Voltage atpillar } 1 \text { (p.u) } \\
\text { Phase }\end{array}$} & \multicolumn{3}{|c|}{$\begin{array}{l}\text { Voltage atpillar } 9 \text { (p.u) } \\
\text { Phase }\end{array}$} \\
\hline & & A & B & C & A & B & $\mathrm{C}$ \\
\hline 0 & 100 & 0.95 & 0.95 & 0.95 & 0.86 & 0.84 & 0.84 \\
\hline 20 & 100 & 0.97 & 0.96 & 0.96 & 0.90 & 0.86 & 0.86 \\
\hline 35 & 100 & 0.97 & 0.96 & 0.97 & 0.92 & 0.88 & 0.87 \\
\hline 50 & 90 & 0.99 & 0.98 & 0.98 & 0.96 & 0.92 & 0.90 \\
\hline 50 & 50 & 1.0 & 1.0 & 1.0 & 1.02 & 1.0 & 0.97 \\
\hline 70 & 45 & 1.01 & 1.01 & 1.0 & 1.05 & 1.01 & 0.98 \\
\hline 70 & 25 & 1.03 & 1.02 & 1.01 & 1.08 & 1.05 & 1.0 \\
\hline 100 & 20 & 1.05 & 1.04 & 1.02 & 1.11 & 1.07 & 1.03 \\
\hline 100 & 0 & 1.05 & 1.05 & 1.03 & 1.19 & 1.12 & 1.06 \\
\hline
\end{tabular}

interests or personal relationships that could have appeared to influence the work reported in this paper.

\section{Acknowledgement}

J.P.S. Catalão acknowledges the support by FEDER funds through COMPETE 2020 and by Portuguese funds through FCT, under POCI-010145-FEDER-029803 (02/SAICT/2017).

\section{References}

[1] R. Tonkoski, L.A.C. Lopes, Voltage regulation in radial distribution feeders with high penetration of photovoltaic, IEEE Energy 2030 Conference, 2008, pp. 1-7.

[2] A.N. Hasan, N. Tshivhase, Voltage regulation system for OLTC in distribution power systems with high penetration level of embedded generation, Int. Trans. Electr. Energy Syst. 29 (7) (2019) Jul..

[3] J.E. Quiroz, M.J. Reno, R.J. Broderick, Time series simulation of voltage regulation device control modes, 2013 IEEE 39th Photovoltaic Specialists Conference (PVSC), 2013, pp. 1700-1705.

[4] M.M. Begovic, I. Kim, D. Novosel, J.R. Aguero, A. Rohatgi, Integration of photovoltaic distributed generation in the power distribution grid, 2012 45th Hawaii International Conference on System Sciences, 2012, pp. 1977-1986.

[5] H. Markiewicz and A. Klajn, "Voltage disturbances standard EN 50160," vol. 5.4.2, p. undefined-undefined, 2004.

[6] V. Behravesh, R. Keypour, A. Akbari Foroud, Control strategy for improving voltage quality in residential power distribution network consisting of roof-top photovoltaic-wind hybrid systems, battery storage and electric vehicles, Sol. Energy 182 (2019) 80-95. Apr.

[7] S. Pukhrem, M. Basu, M.F. Conlon, K. Sunderland, Enhanced network voltage management techniques under the proliferation of rooftop solar PV Installation in low-voltage distribution network, IEEE J. Emerg. Sel. Top. Power Electron. 5 (2) (2017) 681-694 Jun..

[8] P. Mishra, A.K. Pradhan, P. Bajpai, Voltage control of PV inverter connected to unbalanced distribution system, IET Renew. Power Gener. 13 (9) (2019) 1587-1594 Jul..

[9] "Power generating plants in the low voltage grid (VDE-AR-N 4105), VDE VERLAG GMBH, Berlin, Germany," 2019.

[10] J.H. Braslavsky, J.K. Ward, L. Collins, A stability vulnerability in the interaction between Volt-VAR and Volt-Watt response functions for smart inverters, 2015 IEEE Conference on Control Applications, 2015, pp. 733-738.

[11] J.H. Braslavsky, L.D. Collins, J.K. Ward, Voltage stability in a grid-connected inverter with automatic Volt-Watt and Volt-VAR functions, IEEE Trans. Smart Grid 10 (1) (2019) 84-94 Jan..

[12] A.R. Jordehi, Optimisation of demand response in electric power systems, a review, Renew. Sustain. Energy Rev. 103 (2017) 308-319 Sept.2019.

[13] S.H. Madaeni, R. Sioshansi, Using demand response to improve the emission benefits of wind, IEEE Trans. Power Syst. 28 (2) (2013) 1385-1394.

[14] S. Shao, M. Pipattanasomporn, S. Rahman, Grid integration of electric vehicles and demand response with customer choice, IEEE Trans. Smart Grid 3 (1) (2012) 543-550.

[15] C. Chen, J. Wang, Y. Heo, S. Kishore, MPC-based appliance scheduling for residential building energy management controller, IEEE Trans. Smart Grid 4 (3) (2013) 1401-1410.

[16] S. Li, D. Zhang, A.B. Roget, Z. O'Neill, Integrating home energy simulation and dynamic electricity price for demand response study, IEEE Trans. Smart Grid 5 (2) (2014) 779-788.

[17] K. Dehghanpour, M. Hashem Nehrir, J.W. Sheppard, N.C. Kelly, Agent-based modeling of retail electrical energy markets with demand response, IEEE Trans. Smart Grid 9 (4) (2018) 3465-3475.

[18] A. Nikoobakht, J. Aghaei, M. Shafie-Khah, J.P.S. Catalão, Assessing increased flexibility of energy storage and demand response to accommodate a high penetration of renewable energy sources, IEEE Trans. Sustain. Energy 10 (2) (2019) 659-669.

[19] Y. Guo, et al., Machine learning-based thermal response time ahead energy demand prediction for building heating systems, Appl. Energy 221 (March) (2018) 16-27.

[20] N.U. Hassan, et al., Framework for minimum user participation rate determination to achieve specific demand response management objectives in residential smart grids, Int. J. Electr. Power Energy Syst. 74 (2016) 91-103.

[21] N. Ul Hassan, Y.I. Khalid, C. Yuen, W. Tushar, Customer engagement plans for peak load reduction in residential smart grids, IEEE Trans. Smart Grid 6 (6) (2015) 3029-3041.

[22] P.T. Baboli, M. Eghbal, M.P. Moghaddam, H. Aalami, Customer behavior based demand response model, IEEE PES General Meeting, 2012, pp. 1-7.

[23] "Power companies dangle free nights and weekends - CBS News." [Online]. Available: https://www.cbsnews.com/news/power-companies-dangle-free-nightsand-weekends/. [Accessed: 18-May-2019].

[24] "European Commission - PRESS RELEASES - Press release -Commission welcomes political agreement on conclusion of the clean energy for all Europeans package." [Online]. Available:http://europa.eu/rapid/press-release_IP-18-6870_en.htm. [Accessed: 18-May-2019].

[25] "Survey shows utility-customer relationship hinges on a few key moments MarketWatch." [Online]. Available: https://www.marketwatch.com/press-release/ survey-shows-utility-customer-relationship-hinges-on-a-few-key-moments-2015 04-01. [Accessed: 18-May-2019].

[26] N.C. Scott, D.J. Atkinson, J.E. Morrell, Use of load control to regulate voltage on distribution networks with embedded generation, IEEE Trans. Power Syst. 17 (2) (2002) 510-515.

[27] M.G.L.K.P. Neal J. Balu, Power System Stability and Control, McGraw-hill, New York, 1994.

[28] Q. Tao, D. Wang, B. Yang, H. Liu, S. Yan, Voltage control of distribution network with distributed generation based on voltage sensitivity matrix, 2018 IEEE International Conference on Energy Internet (ICEI), 2018, pp. 298-302.

[29] "Engineering Recommendation G100Issue 1 Amendment 2 2018Technical requirements for customer export limiting schemes," no. 1, pp. 1-39, 2018.

[30] K. Sunderland, M. Coppo, M. Conlon, R. Turri, A correction current injection method for power flow analysis of unbalanced multiple-grounded 4-wire distribution networks, Electr. Power Syst. Res. 132 (2016) 30-38.

[31] "EPRI | Smart grid resource center \&gt; simulation tool - OpenDSS." [Online]. Available:http://smartgrid.epri.com/SimulationTool.aspx[Accessed: 01-Sep-2019]. 